\title{
Chinese Nurses' Ethical Concerns in a Neurological Ward
}

Ping Fen Tang, Camilla Johansson, Barbro Wadensten, Stig Wenneberg and Gerd Ahlström Nurs Ethics 2007; 14; 810

DOI: $10.1177 / 0969733007082140$

The online version of this article can be found at: http://nej.sagepub.com/cgi/content/abstract/14/6/810

\author{
Published by: \\ (S)SAGE \\ http://www.sagepublications.com
}

Additional services and information for Nursing Ethics can be found at:

Email Alerts: http://nej.sagepub.com/cgi/alerts

Subscriptions: http://nej.sagepub.com/subscriptions

Reprints: http://www.sagepub.com/journalsReprints.nav

Permissions: http://www.sagepub.co.uk/journalsPermissions.nav

Citations http://nej.sagepub.com/cgi/content/refs/14/6/810 


\title{
Chinese NuRses' ETHICAL CONCERNS IN A NEUROLOGICAL WARD
}

\author{
Ping Fen Tang, Camilla Johansson, Barbro Wadensten, \\ Stig Wenneberg and Gerd Ahlström
}

Key words: Chinese nurses; content analysis; ethical dilemma; moral distress; neuroscience nursing; work stress

Our aim was to describe Chinese nurses' experiences of workplace distress and ethical dilemmas on a neurological ward. Qualitative interviews were performed with 20 nurses. On using latent content analysis, themes emerged in four content areas: ethical dilemmas, workplace distress, quality of nursing and managing distress. The ethical dilemmas were: (1) conflicting views on optimal treatment and nursing; (2) treatment choice meeting with financial constraints; and (3) misalignment of nursing responsibilities, competence and available resources. The patients' relatives lacked respect for the nurses' skills. Other dilemmas could be traced to the transition from a planned to a market economy, resulting in an excessive workload and treatment withdrawal for financial reasons. Lack of resources was perceived as an obstacle to proper patient care in addition to hospital organization, decreasing the quality of nursing, and increasing moral and workplace distress. The nurses managed mainly by striving for competence, which gave them hope for the future.

\section{Introduction}

Nursing is a stressful occupation, ${ }^{1}$ and various factors have been perceived by nurses to be stressful. ${ }^{2}$ The major sources of stress for Chinese nurses are work overload and inadequate staffing, interpersonal relationships, and dealing with hospital administration. ${ }^{3}$ In addition, the modernization of Chinese society and the concurrent reformation and restructuring of the Chinese health care system $^{4}$ is indirectly contributing to increased workplace distress..$^{5}$ The organization and financing of health care is changing, moving away from government-controlled and funded systems to market-based medical practice. ${ }^{6,7}$ The focus and resources of health care are being steered away from low-cost prevention to expensive high-tech equipment and medical procedures, which, together with ongoing privatization have led to more

Address for correspondence: Professor Gerd Ahlström, School of Health Sciences, Jönköping University, PO Box 1026, SE-551 11 Jönköping, Sweden. Tel: + 46 36101196; Fax: + 46 36101180; E-mail: gerd.ahlstrom@hhj.hj.se 
inequality of access to health care. ${ }^{4}$ Basic medical care has simply become too expensive and many patients do not have medical insurance coverage, especially in the rural areas, which causes ethical dilemmas for the health care personnel caring for these patients. ${ }^{7}$ Ethical dilemmas in nursing have so far been mainly related to the aggressiveness of treatment, ${ }^{8}$ and have not yet been systematically studied in China. A dilemma can be defined 'as a difficult problem seemingly incapable of a satisfactory solution or a situation involving a choice between equally unsatisfactory alternatives' (p. 6). ${ }^{9}$ In addition, no research on occupational stress and ethical concerns in a neurological setting has been performed. Neuroscience nurses are caring for patients with severe neurological conditions involving a complex mix of sensorimotor, cognitive and emotional impairments. ${ }^{10,11}$ These illnesses have a great impact on patients' lives and on the lives of their next of kin, challenging neuroscience nurses to be proficient in handling life-threatening situations, rehabilitation and lifelong palliative care. In the light of this, the aim of the present study was to describe Chinese nurses' experiences of ethical problems and workplace distress in a neurological ward.

\section{Method}

\section{Settings and participants}

This study was performed in a medical teaching hospital in southwest China. The interviewees worked in a neurological department consisting of two wards employing 42 nurses in total. The data collection was restricted to a period of two days; 22 nurses working the day shift during that time were eligible and asked to participate in this qualitative interview study, 20 of whom accepted.

\section{Procedure and ethical considerations}

The physician in charge of the department and the head nurses gave their permission after being informed about the project. The eligible nurses received information by letter and were also verbally informed about the study by the head nurses. Participation in the study was voluntary and followed the ethical principles for medical research involving human participants, such as informed consent. Confidentiality was assured and the participants had the right to withdraw at any time without any explanation or consequence to themselves.

\section{Interviews}

Two of the Swedish researchers (GA and BW) carried out the interviews in a conversational manner. Two Chinese nurses from another department (HZ and LT) were interpreters and the interviews were held in English. All the interviewees' quoted narratives are in the third person to emphasize the use of interpreters in this interview study. In addition, the interpreters were informed about the aim, research design and main questions of the study, which is important when performing cross-cultural studies where narratives are obtained by means of an interpretational process. ${ }^{12}$ The interview guide consisted of the following general questions: (1) What upsets you at work? (2) When do you feel displeasure at work? (3) What situations at work make 
you sad after a working day? (4) Do you experience ethical issues/dilemmas in your work? If yes, can you give an example of a situation where such an issue/dilemma occurred? (5) If yes to question 4, how do you try to cope with such situations? (6) How do you perceive the quality of nursing care in your unit? (7) Do you experience a discrepancy between the actual quality of nursing care at your unit and the desirable quality? (8) If yes to question 7, how do you try to cope with this discrepancy? (9) What in the hospital environment is an obstacle to solving ethical issues/dilemmas at your work? Additional individualized follow-up questions were asked, their scope and number depending on how precisely and fully the person had answered the general questions. The interviews lasted between 45 and 60 minutes and were audiorecorded. A secretary experienced in English and qualitative methods transcribed them verbatim.

\section{Analytical procedure}

An inductive method of analysis (latent content analysis) was used, which involves interpretation of the underlying meaning of a text. ${ }^{13,14}$ The interviews were first listened to in their entirety to obtain an overall sense of the content. The identification and marking of meaning units in each interview took place next. A meaning unit is a group of words that relates to the same central meaning. ${ }^{14}$ In the third step the meaning units were shortened or condensed, then abstracted and labelled with a code in the fourth step. The similarities and differences among the various codes were determined and subthemes were generated from these codes. In addition, different content areas ${ }^{14}$ relating to the interview questions were simultaneously developed; this framework was then used for sorting the meaning units, codes and subthemes. Thereafter the interpretation of the underlying meaning or latent content of the codes and subthemes led to the formulation of themes within each content area. The analysis and interpretation of each meaning unit was scrutinized independently by the researcher most experienced in content analysis (GA). It was also discussed at several meetings between the researcher who carried out the initial analysis (CJ) and the other Swedish researchers (BW and GA). In the final step the results of the analyses of all 20 interviews were compared for similarities and differences. This resulted in refinement of the codes, themes and subthemes. The trustworthiness of the results was further guaranteed by critical scrutiny by the Chinese members of the research team (PFT, HZ, LT and SY). This meant that the results of the analysis were read and scrutinized from the point of view of two different contexts and cultures. ${ }^{12}$ Disagreements between members' interpretations were resolved by referring back to the original transcript to determine the proper meaning and context.

\section{Findings}

Study group background data are presented in Table 1, including educational level. Almost all the interviewees experienced ethical dilemmas and distress in their job to some extent. Content areas and themes are shown in Table 2.

It is interesting that seven of the 20 nurses were generally satisfied with their working conditions and seldom felt upset while working, despite their experiences. They were thus not significantly affected by ethical dilemmas and had satisfactory 
Table 1 Participants' background data $(n=20)$

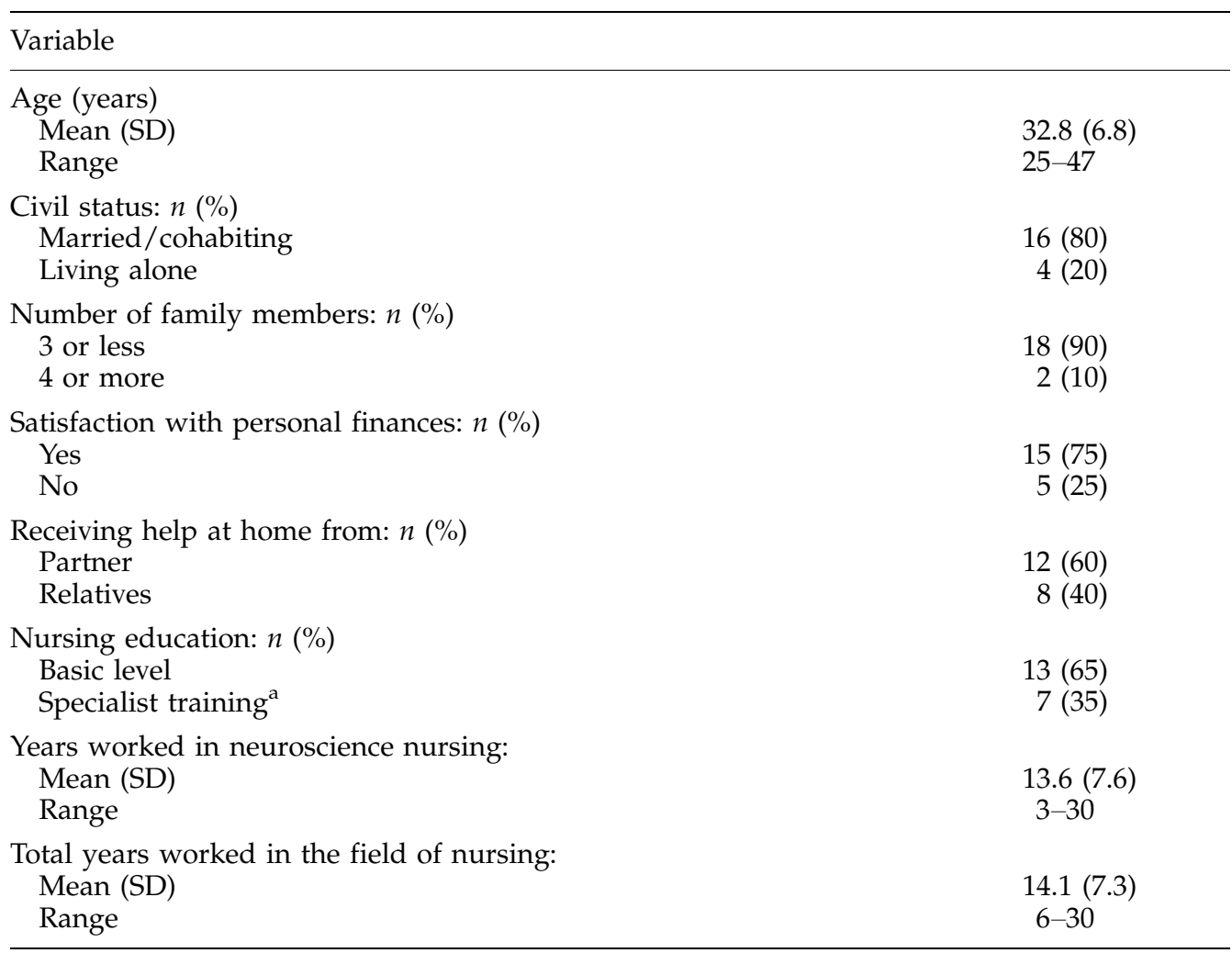

ane of whom had a Bachelor's degree in nursing.

interpersonal relationships at work. They were optimistic about the future and rather pleased with the newly built hospital that facilitated patient health education courses. However, the aim of this study was to examine the phenomenon of ethical dilemmas and work stress in China. The main focus of the present article will therefore be on the collective experiences related to typical ethical dilemmas encountered in clinical practice, the resulting distress and its influence on quality of care and the nurses' efforts to cope with the situation.

\section{Ethical situations}

Conflicting views on optimal treatment and nursing

The nurses experienced ethical dilemmas on occasions when they were unable to give appropriate care because the relatives and the patients distrusted their professional skills and did not consent to the proposed treatment, even when prescribed by a doctor. The nurses narrated that in some cases the relatives refused life-sustaining measures despite nurses' efforts to make them reconsider.

When she saw the patient was having difficulty breathing she felt so helpless because of the relatives; they just wouldn't consent to her starting the treatment. 
Table 2 Participant nurses' experiences

\begin{tabular}{|c|c|c|}
\hline Content area & Theme & $\begin{array}{l}\text { No. meaning } \\
\text { units }\end{array}$ \\
\hline Ethical dilemmas & $\begin{array}{l}\text { Conflicting views on optimal treatment and nursing } \\
\text { Treatment choice meeting with financial constraints } \\
\text { Misalignment of nursing responsibilities, competence } \\
\text { and available resources }\end{array}$ & $\begin{array}{l}28 \\
12 \\
10\end{array}$ \\
\hline Workplace distress & $\begin{array}{l}\text { Excessive demands coupled with lack of influence } \\
\text { Lack of communication, respect and appreciation } \\
\text { Influence of the work situation on health }\end{array}$ & $\begin{array}{l}60 \\
47 \\
26\end{array}$ \\
\hline Quality of nursing & $\begin{array}{l}\text { Measures used to achieve high quality nursing } \\
\text { Lack of nurses, knowledge and communication } \\
\text { reduce nursing quality } \\
\text { Reflections on ways to increase nursing quality } \\
\text { Improved hospital management necessary for higher } \\
\text { nursing quality }\end{array}$ & $\begin{array}{l}33 \\
28 \\
26 \\
12\end{array}$ \\
\hline Managing distress & $\begin{array}{l}\text { Striving for competence - hope for the future } \\
\text { Striving for better communication and improved } \\
\text { co-operation } \\
\text { Avoiding conflicts through aquiescence } \\
\text { Striving for relaxation and family support }\end{array}$ & $\begin{array}{r}39 \\
23 \\
11 \\
7\end{array}$ \\
\hline
\end{tabular}

In order to please both relatives and patients, in many of these situations the nurses were forced to act contrary to their own opinion, superior knowledge and prudent medical reasoning, and sometimes even against doctors' orders. Relatives ignored the rules of no admittance to the monitoring room and would also question the nurses' interventions, for example, when encouraging the patient to practise swallowing techniques, and when performing bladder irrigation or placing a gastric tube. The nurses always attempted to protect the patient and would not disclose the patient's health status to a relative against the patient's wishes. However, this was sometimes difficult to comply with and presented them with an ethical dilemma. The nurses thought on occasion that the doctors did not support them and respect their knowledge when they voiced a different opinion with regard to treatment, placing them in the position of having to carry out orders they did not consider appropriate and useful.

Treatment choice meeting with financial constraints

The nurses also experienced an ethical predicament when the patient or relatives could not afford desperately needed treatment, for instance involving the use of a ventilator.

When it comes to some critically ill cases, sometimes the relatives don't want to save the patient's life because they don't have enough money, they don't have the economic foundation. They have no money. They are from the countryside, maybe, and it's hard to support the patient. The patient uses a mechanical ventilator to breathe, but the relatives come and remove it from the patient.

In such difficult situations the nurses felt helpless because they knew they could have helped the patient. This helplessness was combined with empathy for the patient, 
especially if he or she was very young, and led to a difficult inner conflict. To add insult to injury, the nurses received complaints related to these economic issues, over which they had no influence, thus increasing their level of frustration. The nurses were aware of the difficulty of providing high quality health care for every citizen, but in certain cases they thought a reduced fee was justified. The present health care system was regarded as unfair and as promoting inequality. Sometimes nurses and doctors had conflicting views concerning which patients were to be admitted first, as when doctors reserved hospital beds for affluent patients.

Misalignment of nursing responsibilities, competence and available resources

Having too many patients and not enough time created ethical dilemmas because nurses are responsible for each and every patient. Not being able to care properly for patients on ventilation support was a typical dilemma. In addition, they did not always have the knowledge needed to handle clinical problems or to operate new equipment.

They have got ever so many pieces of advanced equipment, monitoring equipment. But they don't understand them very well; they are not good at controlling all the machines. So they really hope that they can have more lessons and study more about these electric machines, to get more knowledge.

Lack of time, resources or training to perform their nursing responsibilities satisfactorily affected their job performance negatively. For instance, the nurses were severely reprimanded if any pressure sores were detected, despite the fact that the shortage of nurses reduced the time available to care properly for patients. Another example of the mismatch between responsibility and capability was in patient education situations when the nurses felt a lack of the competence needed to support the patient adequately.

A lot of diabetic patients are admitted to her department and nurses need to know about the diet for this kind of disease. She gives them the diet education, but she knows she's not an expert in diet education. So sometimes she just explains that she's not an expert and just gives all the information she has to the patients.

\section{Workplace distress}

Excessive demands coupled with lack of influence

Distress was experienced when caring for seriously ill patients in addition to a demanding workload, especially when the nurses' superiors were not available for consultation and support. Then they just had to manage on their own, prioritizing tasks and doing their best despite being overwhelmed with stress. This was compounded by a sense of powerlessness because usually they could not influence medical care decisions, but nevertheless bore the main responsibility regarding the patient. This made them angry and frustrated, particularly when they received unfair criticism in difficult cases or when they had to solve conflict between the doctor and the patient/relatives. Nurses became frustrated when doctors gave their orders verbally because this was against the rules. On the night shift the nurses were especially vulnerable to the effects of stress such as feelings of insecurity and anxiety, compromising the safety of their patient care when there was insufficient backup because of a lack of nurses or of supervision from the head nurse. 
For example she's a young nurse in the department; she was doing the night shift. Just when she began, three patients were admitted to the ward. She had to take care of the three patients at the same time as another patient needed the drip changed. She didn't know how to cope with it all, everything was a big mess.

The shortage of resources, especially the lack of nurses, made it nearly impossible to meet the standards of good care without sometimes doing overtime. Not having the time to comply with rules and regulations, as well as organizational duties in the form of reports and time-consuming work planning, were additional stressors. The nurses perceived the rapid development of modern medicine in China as the reason why patients now have high expectations regarding the care received.

The patients' and relatives' demands increase more and more and the nurses need to learn more and more, and more and more new techniques are coming to the hospital, so they feel stress. It's getting harder and harder.

A final demand on the nurses was the training of new nurses as well as performing their own regular duties, which in the end meant less time for the patients. The nurses felt frustrated when they had to ask the relatives for help with patients' basic care because of the increased workload.

\section{Lack of communication, respect and appreciation}

The nurses told of many situations in which a patient or the relatives did not understand them and conflict arose that interfered with the care. This failure of communication and the difficulty of resolving misunderstandings were unsettling. In addition, disagreeing with doctors and managers about treatment-related issues was an irritation and so the nurses were reluctant to have their say in these matters. This, coupled with a lack of respect from doctors, patients, relatives and managers, increased the nurses' stress level and frustration. The patients always trusted the doctors in preference to the nurses; likewise the managers always questioned the nurses, never the doctors when there was a problem. Despite this, the nurses still tried hard to meet patients' need for care, but seldom received the appropriate appreciation; quite the opposite. They could receive unfair criticism, having to take the blame in difficult situations when in reality it was the doctors who were to blame. These tough working conditions were believed to be a direct consequence of nurses' low social standing in China.

Society looks down on the nurses, and the doctors look down on the nurses. She wants to change these ideas. All this makes her feel unhappy and she feels a lot of stress in her work. Society, the doctor, the patients and the relatives - they don't have a very good understanding of nurses. That causes stress in her job.

\section{Influence of the working situation on health}

The daily experiences of distress and frustration were described in terms of physical and psychological problems. Some of the nurses anticipated that they would give up their jobs before retirement age because of deteriorating physical health. Some even had difficulty in relaxing in their spare time. The inadequate working conditions and work pressure resulted in overtime, exhaustion and lower confidence in their ability to perform their work satisfactorily. They often worried about the opinions of patients or doctors and became sad when patients were dissatisfied with their care. They were afraid of making mistakes, especially failing to stay focused in urgent situations with critically ill patients. 
In her department there are a lot of critical cases, so when she comes to work she feels stress around her. She feels unhappy and sometimes she doesn't want to work and doesn't want to go to work.

Even the possibility of making minor mistakes generated stress in the nurses because they feared the head nurse's comments. A sense of powerlessness was common with regard to their ability to influence the managers as the nurses' concern for their own working situation or patient safety went unheard. Consequently, they did not usually ask for help until the work situation became impossible to handle, which compounded the sense of mental strain and personal inadequacy. The nurses knew it was not possible to save everyone but still felt sad and helpless, especially when a terminal disease had struck a young patient. They took on themselves some measure of responsibility for their patients' sufferings and it was very difficult when money influenced treatment alternatives.

\section{Quality of nursing}

Measures used to achieve a high quality of nursing

The quality of nursing was measured in terms of patient recovery and lack of complications. In addition, the importance of patients' and relatives' satisfaction was emphasized and their expectations increased the pressure to deliver high quality care.

She thinks there are two parts to it. One part is whether the patient is satisfied with their work - that's the most important one. The other is whether the patient comes back to the hospital again, or if they would be willing to come back.

Basic nursing standards, which require continuous observations, were used as a yardstick to achieve care of good quality. On the basis of the patient's nursing diagnosis, a nursing plan was formulated and implemented. This process was documented in the nursing records. Every morning the nurses checked the patients' condition, and if problems were detected, nursing interventions were carried out. Treating pressure sores was a priority, especially as these were not allowed to happen. Several times a day inspections for any sign of pressure sores were performed. The head nurse daily supervised the performance of the clinical work and her opinion was a good measure of the nursing quality achieved, as was the doctors' acceptance of nursing. Nevertheless the nurses believed that the desired level of quality was not always attained, even though patient satisfaction had actually been rising and patients' rights were now better protected than before.

Lack of nurses, knowledge and communication reduce nursing quality

There were several challenges to overcome in order to achieve high quality nursing care, one of which was the shortage of nurses. This was particularly evident on the night shift, even to the point that the quality of care was felt to be compromised. Nursing quality suffered as a result of the excessive workload. Patients had to wait longer for their call bells to be answered and seldom had the chance to talk to nurses about their feelings. Sometimes the relatives had to help with basic patient care, thereby lowering the quality of care. 
They are short of nurses, so they can't do everything carefully. They can't do basic nursing care well, so they can't get good results.

Another challenge was the lack of knowledge previously described, such as the lack of training to operate new equipment, which meant that other nurses had to provide help, therefore reducing the time they had available for patients. There was not enough time to inform patients and relatives properly, leading to a lack of co-operation because they did not always understand and follow the nurses' instructions. The end result was a lower quality of nursing, which also was the case if communication problems existed among the medical staff.

Reflections on ways to increase nursing quality

Aspirations to achieve high quality nursing care were evident in the interviews. The nurses emphasized the importance of giving basic and necessary nursing care to every patient, of being flexible in prioritizing patient needs and of treating patients with empathy. In addition, the nurses' theoretical and clinical skills were improving every year, as could be seen from the yearly examination results. However, more nurses needed to be employed in order to bring down the workload for each nurse. This would enable the nurses to enroll in continuing education while at work, instead of having to study in their spare time, which in any case was not an option for most of the nurses for financial reasons. Another consequence of a decreased workload would be more time available for patient education and preventive nursing measures. Improved communication and decreased anxiety for patients and relatives were the anticipated outcomes of more time spent on health education, leading to a higher quality of care.

She thinks most of it has to do with the patients and the patients' relatives. It's a question of paying more attention to health education so that the patients and the relatives have got more knowledge about medication and how to take good care of themselves.

The nurses were also self-critical and expressed the need for a change of attitude towards patients. Patients need to be seen as whole persons, not just as bodies. There was room for improving the treatment of pressure sores, for instance by having clean sheets and by checking wounds more often.

\section{Improved hospital management necessary for higher nursing quality}

The management system was experienced as bureaucratic and hierarchic. The system on the wards was considered to be less than optimal, especially for nurses and patients, benefiting only the doctors. This system substantially prolonged treatment waiting time and the discharge process. For example, staff had to have personal contacts among the staff of other departments to be able to facilitate patients being discharged properly by the discharge department.

Sometimes it doesn't depend just on them, it also depends on how some other departments co-operate with them. For example, if the patient is discharged today, they need to catch the plane or bus to go home, but in the discharge department they need time to do all the formalities. So the patient is standing there telling them 'please hurry, please hurry'. 
Increased collaboration between departments with a focus on the best interest of patients was suggested as necessary for increasing nursing quality.

\section{Managing distress}

Striving for competence - hope for the future

In spite of a demanding job and lack of resources, the nurses assumed great responsibility. This showed in many different ways, for instance in working overtime and even volunteering their own time and money to help poor patients. They tried to solve problems on their own before asking other nurses for help. Nurses carefully obeyed all the hospital policies, but on occasion used personal contacts to help their patients, as described in the previous section. One of the most obvious signs of responsibility was their focus on knowledge and education in view of the fast development of medical knowledge and technology in China. Consequently, they felt the need to update and improve their nursing skills continually through higher education and training. They hoped to achieve this in the future with the support of the hospital because many of the existing problems could be solved by increased nursing competence. With more knowledge they would also hope to be able to cope better with problems and new work assignments. There was also a hope that nurses' status in society, as well as their salary, would then increase.

She thinks they should improve their knowledge, especially that nurses should be skilled and educated. They should have the same degrees as the doctors. Maybe in that way all the problems will be solved.

As nursing is a profession in its own right, there was an awareness of the importance of not solely relying on doctors' opinions in matters related to nursing and of being more patient focused in order to raise the quality of nursing care.

\section{Striving for better communication and improved co-operation}

Improved communication with patients and relatives was believed to be achievable through patient focused education or with the assistance of colleagues and other medical staff. This realization had prompted nurses to ask increasingly for help to improve co-operation when relatives did not agree with the proposed treatment. The head nurse and nurses of other departments were also being used as resources.

She'll ask for help. During the day shift she can ask for the senior nurse, and if during evening shift maybe she can just ask for nurses from another department.

Communication and exchange of knowledge were seen as ways of spreading expert nursing practices throughout the hospital, which would benefit patients in all departments. In addition, the doctors could be called upon to explain the benefits of the treatment to patients and relatives. However, relationships with the doctors were problematic. The nurses told of many situations in which they felt the responsibility to initiate communication in order to prevent misunderstanding, even when the nurses disagreed with the doctors about the right course of action. Nevertheless, the importance of a good working relationship between nurses and doctors was stressed, and the nurses hoped for better communication and cooperation in the future. 
She thinks first of all that a good relationship between the doctors and nurses should be established; that's the first step. They should observe the condition of the patient together, and solve the problems together, and meet the patients' and relatives' needs to achieve a higher quality of nursing.

\section{Avoiding conflict through acquiescence}

The nurses recounted their efforts to retain a positive and calm attitude towards patients at all times, despite being upset, in order to attempt to reduce stress in the working environment. Acquiescence was also often used as a coping strategy when nurses had to follow doctors' orders despite having a different opinion. They could instead monitor seriously ill patients more closely if they had any misgivings about the prescribed treatment, and collect information by following the doctors on their rounds. This kind of acceptance could also mean that the nurses frequently followed relatives' suggestions to avoid conflict. They just took a deep breath and tried to endure and ignore things until the problem was solved. If a doctor had made a mistake, the nurse tried to protect the doctor-patient relationship by avoiding recounting the whole truth of the matter. The nurses also avoided open conflict with doctors regarding fluid intake, adjusting it afterwards if necessary. However, they always followed doctors' orders regarding patients' medication.

She does have some skills and some methods to cope with the pressure sores, and with very good results, but she has to follow the doctor's orders and she has to follow the patients' and relatives' suggestions because she is afraid there will be a conflict.

\section{Striving for relaxation and family support}

Many of the nurses narrated that they coped with work stress by relaxing and doing things they liked in their free time. Being alone for a while at home after work, silently reflecting on the events of the day, enabled them to separate themselves from the feelings of stress accumulated at work and in a relaxed way continue with their daily activities. Another way to achieve distance was by doing things together with family and friends after work. If they needed to talk about their experiences, friends and family encouraged them and gave their support.

She just refuses to think more about it and just does something else, to get rid of it. If she's just come off duty she likes to have a shower and go to sleep or go shopping.

\section{Discussion}

The study's aim was to describe Chinese nurses' experiences of ethical problems and related work distress in a neurological clinical setting. The results were similar to those of previous research on ethical concerns, showing that these contribute to work distress in the health care system, ${ }^{15}$ pointing to the need for reducing their effects in neuroscience nurses' work environment. Excessive workload and unsatisfactory interpersonal relationships at work were key components found in all the content areas, leading to increased distress and decreased performance for the great majority of the interviewed nurses. In addition, having limited influence over their work situation and a work environment lacking in communication created an underlying source for potential ethical dilemmas and conflicts. Different ways of handling the demands and pressures were also narrated. These findings are similar to previous 
studies, showing that Chinese nurses are in general more dissatisfied than satisfied with regard to work, pay and promotion. ${ }^{16,17}$

The main ethical problem encountered in this study, conflicting views on optimal treatment and nursing, was related to interpersonal relationships. The relationships with patients and relatives were ambivalent at best. Wong and Pang ${ }^{18}$ stated that the distrust of nurses' ability to care properly for patients can be traced to the strong Chinese family tradition of taking care of ill family members' daily needs and deciding about their treatment. Conflict and tension loom when family members and nurses do not agree on matters related to patient care. ${ }^{19}$ A typical moral issue faced by Chinese nurses is the practice of treatment withdrawal, which depends on relatives' financial circumstances and the prospect of cure. ${ }^{20}$ The rising inequality of access to health care services during the last 20 years or so $^{4}$ has aggravated this problem and it was experienced as being a significant ethical problem in the current study. Other problems may also be directly related to adaptation to a market economy, such as cost containment in the form of a decreased number of nurses and medical staff. This shortage of resources forced the nurses to prioritize their tasks, reducing overall nursing quality. There was a lack of time to provide proper health education for patients or to keep up with the educational demands imposed by new medical knowledge and technology, a common problem and often a predicament in all nursing specialties. ${ }^{21}$

The findings in the second content area focus on workplace distress. For example, work overload, which has been reported as a major source of stress in Chinese nurses, ${ }^{3}$ caused distress. The ethical or moral situations described above were another important factor contributing to distress. Being an element of occupational stress in nursing, moral distress is defined in the literature as

painful feelings and/or psychological disequilibrium that occurs when nurses are conscious of the morally appropriate action a situation requires, but cannot carry out that action because of institutionalized obstacles: lack of time, lack of supervisory support, exercise of medical power, institutional policy, or legal limits (pp. 636-37). ${ }^{22}$

Nurses may be vulnerable to moral distress because they have high professional responsibility for patient care but limited influence and authority over medical decisions, as was evident in the present study. Not being able to pursue the perceived right course of action generated a sense of helplessness in conjunction with frustration over doctors' air of professional superiority and lack of co-operation. In addition, it has been suggested that competing role requirements due to the rapid restructuring of the health care system are partly to blame for the rising incidence of moral distress in China. When their sense of socialist responsibility for patients collides with the restraints imposed by a market economy, moral tensions develop in nurses. ${ }^{23}$ Another possible cause of the problems encountered in this study is more traditional in nature. There exists an ancient Chinese attitude that nursing is similar to the work of servants, ${ }^{19}$ as recounted by the nurses participating in the present study. The absence of respect and appreciation for nursing skills has been previously documented ${ }^{17,20}$ as inducing a lack of patient co-operation and causing emotional and physical distress in nurses. Signs of moral distress, such as frustration, helplessness, guilt and loss of self-confidence and self-worth, in addition to physical complaints, ${ }^{22}$ were narrated by the nurse respondents.

With limited resources and a difficult work situation, different approaches to handling distress were used, such as striving towards competence - hope for the future. Advanced study is highly valued in Chinese culture, ${ }^{7,24}$ this was reflected 
in the nurses' ambition to become more proficient in their profession through higher education in order to improve their problem-solving abilities. Another interesting finding was the prevalence of avoiding conflict through acquiescence as a method of coping with problematic situations and distress. Co-operation and interpersonal harmony is highly prized in Chinese culture. ${ }^{24}$ By accepting doctors' orders and relatives' suggestions in an accommodating way, nurses could avoid open conflict. This behavior is common in nurses and conflict situations can usually be circumvented and rapport maintained at all cost. ${ }^{25}$ Relief from distress was mostly sought outside the work environment, which has previously been observed in Chinese nurses. ${ }^{3}$

The occurrence of dilemmas and the ensuing moral distress were strongly related to an excessive workload and less than ideal interpersonal work relationships, which lower nursing performance. The nurses themselves emphasized a decrease in the workload as the most important issue with regard to nursing care quality and wanted more time to be available for patient care and health education. Such measures have been shown to improve the quality of care. ${ }^{26}$ Maintaining nursing records and carefully monitoring the effects of nursing care were administrative tasks that ensured a high quality of care. However, the management system was considered too bureaucratic and inefficient. Both nurse and work environment characteristics are believed to contribute to moral distress, ${ }^{8}$ thus there is also a need for changes in both management style and the nursing work environment. ${ }^{17}$ With increased job satisfaction, the effects of work and moral stress may be eased. ${ }^{27}$ Another way to reduce moral distress would be the instigation of nurse ethics rounds, where nurses would be able to discuss ethical dilemmas encountered in clinical practice and develop approaches to prevent their occurrence. ${ }^{9}$

With regard to the trustworthiness of the data, three of the Swedish researchers, one with extensive experience in qualitative research (GA), jointly performed the main part of the analysis. This ensured high credibility with regard to how well the data and the analysis addressed the intended focus of the study. ${ }^{14}$ The language used for the data collection was English, but the researchers' native language was either Chinese or Swedish. If the interviewer and the interpreter have different source languages and one common language, there is a potential threat to trustworthiness at various points in the interview and analytical processes. ${ }^{28}$ The Chinese researchers therefore verified the results by reading the transcribed interviews and scrutinizing each step of the analysis. Cultural competence deriving from an ethnically diverse research team minimizes the threat to trustworthiness. ${ }^{12,29,30}$

\section{Conclusions}

No previous study results have been reported on ethical dilemmas and workplace distress experienced by neuroscience nurses, therefore the present study contributes new knowledge in this area. The findings highlight the challenges faced by Chinese nurses when dealing with patients, relatives and doctors without themselves being reduced to servants. ${ }^{7}$ Another important issue is that of the organization's ability to provide the resources and structures needed to decrease workplace and moral distress through the reduction of work overload and the occurrence of ethically difficult situations. ${ }^{15}$ The findings of this study hint at the complex relationship between ethical dilemmas and distress because one third of the interviewees were still 
able to manage their work situation satisfactorily. Future quantitative studies on the factors influencing the impact of ethical dilemmas in the workplace are therefore recommended.

\section{Acknowledgements}

The authors gratefully acknowledge the financial support of Kunming Medical College in China, and the Centre for Nursing Research, Örebro University Hospital, Sweden. We would also like to thank Haiyan Zhang (HZ) and Long Ting (LT) who translated the interview guide into Chinese, worked as interpreters of the interviews, and validated the results of the analysis. In addition, we wish to express our gratitude to Su Yan (SY) for her work with translation and validation, and to all the nurses who generously participated and willingly shared their experiences in the interviews.

Ping Fen Tang, Kunming Medical College, Kunming, Province of Yunnan, China.

Camilla Johansson and Stig Wenneberg, Örebro University, Örebro, Sweden.

Barbro Wadensten, Gävle University, Gävle, Sweden.

Gerd Ahlström, Jönköping University, Jönköping, Sweden.

\section{References}

${ }^{1}$ Clegg A. Occupational stress in nursing: a review of the literature. J Nurs Manage 2001; 9: 101-106.

2 Dolan SL, van Ameringen MR, Corbin S et al. Lack of professional attitude and role problems as correlates of propensity to quit amongst nursing staff. J Adv Nurs 1992; 17: 1455-59.

${ }^{3}$ Callaghan P, Tak-Ying SA, Wyatt PA. Factors related to stress and coping among Chinese nurses in Hong Kong. J Adv Nurs 2000; 31: 1518-27.

${ }^{4}$ Smith CJ. Modernization and health care in contemporary China. Health Place 1998; 4: 125-39.

${ }^{5}$ Lim MK, Yang H, Zhang T et al. China's evolving health care market: how doctors feel and what they think. Health Policy 2004; 69: 329-37.

${ }^{6}$ Ho LS. Market reforms and China's health care system. Soc Sci Med 1995; 41: 1065-72.

7 Pang SM. Nursing ethics in modern China - conflicting values and competing role requirements. Amsterdam: Rodopi, 2003.

${ }^{8}$ Fry ST, Harvey RM, Hurley AC et al. Development of a model of moral distress in military nursing. Nurs Ethics 2002; 9: 373-87.

9 Davies AJ, Aroskar MA, Liaschenko J et al. Ethical dilemmas and nursing practice, fourth edition. London: Prentice Hall, 1997.

10 Banich MT. Cognitive neuroscience and neuropsychology, second edition. Boston, MA: Houghton Mifflin, 2004.

${ }^{11}$ Hickey JV. The clinical practice of neurological and neurosurgical nursing, fifth edition. Philadelphia, PA: Lippincott Williams \& Wilkins, 2003.

12 Wallin A-M, Ahlström G. Cross-cultural interview studies with interpreter: a systematic literature review. J Adv Nurs 2006; 55: 723-35.

13 Downe-Wamboldt B. Content analysis: methods, applications and issues. Health Care Women Int 1992; 13: 313-21.

${ }^{14}$ Graneheim UH, Lundman B. Qualitative content analysis in nursing research: concepts, procedures and measures to achieve trustworthiness. Nurse Educ Today 2004; 24: 105-12.

15 Kälvemark S, Höglund AT, Hansson MG et al. Living with conflicts - ethical dilemmas and moral distress in the health care system. Soc Sci Med 2004; 58: 1075-84.

16 Wang Y. Job satisfaction of nurses in hospital. Chin J Nurs 2002; 37: $593-94$ (in Chinese). 
$17 \mathrm{Hu}$ J, Liu H. Job satisfaction among nurses in China. Home Health Care Manage Pract 2004; 17(1): 9-13.

${ }^{18}$ Wong T, Pang SM. Holism and caring: nursing in the Chinese health care culture. Holist Nurs Pract 2000; 15(1): 12-21.

19 Pang SM, Gordon A, Wong T. Drawing a qualitative distinction of caring practices in a professional context: the case of Chinese nursing. Holist Nurs Pract 2000; 15(1): 22-31.

20 Pang SM. Nursing ethics in modern China - conflicting values and competing role requirements. Amsterdam: Rodopi, 2003: 133-73.

${ }^{21}$ Bucknall T, Thomas S. Nurses' reflections on problems associated with decision-making in critical care settings. J Adv Nurs 1997; 25: 229-37.

${ }^{22}$ Corley MC. Nurse moral distress: a proposed theory and research agenda. Nurs Ethics 2002; 9(6): 636-50.

23 Pang SM. Nursing ethics in modern China - conflicting values and competing role requirements. Amsterdam: Rodopi, 2003: 87-31.

${ }^{24}$ Tsai SL. Chinese nurse stress in Taiwan. Issues Ment Health Nurs 1993; 14: 275-85.

${ }^{25}$ Oddi LF, Cassidy VR, Fisher C. Nurses' sensitivity to the ethical aspects of clinical practice. Nurs Ethics 1995; 2: 197-209.

${ }^{26}$ Blegen M, Vaughn T. A multi-site study of nursing staff and patient outcomes. Nurs Econ 1998; 16: 196-203.

27 Corley MC, Minick P, Elswick RK et al. Nurse moral distress and ethical work environment. Nurs Ethics 2005; 12: 381-90.

${ }^{28}$ Kapborg I, Berterö C. Using an interpreter in qualitative research: does it threaten validity? Nurs Inq 2002; 9(1): 52-56.

29 Gil EF, Bob S. Culturally competent research: an ethical perspective. Clin Psychol Rev 1999; 19: $45-55$.

30 Tsai JHC, Choe JH, Lim JMC et al. Developing culturally competent health knowledge: issues of data analysis of cross-cultural, cross-language qualitative research. Int J Qualitative Methods 2004; 3(4): article 2. Retrieved 5 March, 2007, from: http://www.ualberta.ca/ iiqm/ backissues/3_4/pdf/tsai.pdf. 